\title{
ECH OF SPUR GEARS - A STEP TOWARDS COMMERCIALIZATION
}

\author{
MiSRA, J. P.; JAIN, P. K. \& SEVAK, R.
}

Abstract: ECH of gears is a productive, high accuracy, micro-finishing, long tool life gear finishing process in which material is removed by combined action of electrolytic dissolution and scrubbing action of abrasive grains. This chapter focuses the comprehensive study carried out for commercializing the process ECH of gears by modifying the existing experimental setup. A comparative study of the existing and recently developed experimental setups, how both the setups work and their outcomes are discussed elaborately in this chapter. The benefits of the recently developed experimental setup have also been highlighted to establish the viability of employing it for ECH of gears over existing setup.

Key words: gears, ECM, honing, ECH, gear finishing
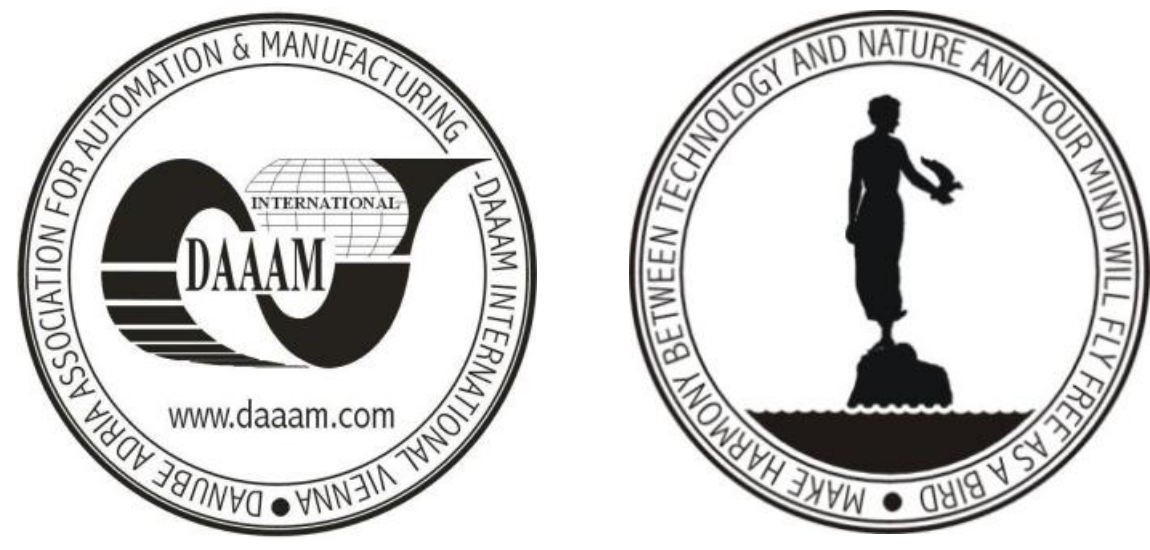

Authors' data: Misra, J[oy] P[rakash], Jain, P[ramod] K[umar] \& Sevak, R[avi], Mechanical \& Industrial Engineering Department, Indian Institute of Technology Roorkee, India, joyprakash.misra@gmail.com,_pjainfme@iitr.ernet.in, jpmisra@in.com

This Publication has to be referred as: Misra, J[oy] P[rakash]; Jain, P[ramod] K[umar] \& Sevak, R[avi] (2012). ECH of Spur Gears - A Step Toward Commercialization, Chapter 17 in DAAAM International Scientific Book 2012, pp. 197-212, B. Katalinic (Ed.), Published by DAAAM International, ISBN 978-3901509-86-5, ISSN 1726-9687, Vienna, Austria

DOI: 10.2507/daaam.scibook.2012.17 
Misra, J. P.; Jain, P. K. \& Sevak, R.: Ech of Spur Gears - A Step Towards Commer...

\section{Introduction}

Gears have received special attention from the technical community for more than two millennia due to their unique contribution to the operation of so many machines and mechanical devices. It is used to transmit motion and/or power mechanically and positively (i.e. without slip) with and without change in the direction and speed of rotation by the successive engagements of teeth on their periphery. It constitutes an economical method for such transmission, particularly if power levels or accuracy requirements are high. Gears can be classified according to six criteria namely (1) according to configuration: external and internal gears; (2) according to axes of transmission: (a) for transmission between parallel shafts: straight toothed spur gear, single helical, and double helical or Herringbone gears, (b) for transmission between intersecting shafts: bevel gears (straight-tooth, spiral-tooth, zero-bevel, crown, and mitre type), (c) for transmission between nonparallel and nonintersecting shafts: spiral gears, hypoid gears, worm and worm wheel; (3) according to pattern of rotation: (a) rotation to rotation, (b) rotation to translation and vice-versa (i.e. rack and pinion); (4) according to peripheral velocity: (a) low velocity, (b) medium velocity, and (c) high velocity; and (5) according to pitch diameter: (a) coarse pitch gear, (b) fine pitch gear, (c) medium pitch gear (6) according to manufacturing precision: based on International Standards there could be around 12 degrees of manufacturing accuracy (Dudley, 1984; Davis 2005). It has wide application areas which include: small gears in precision equipment, clocks, watches, robots and toys, gears for office equipment, appliance gears, machine tool gears, control gears, automotive, transportation, marine and aerospace gears, gears for oil and gas industry, large and heavy duty gear boxes used in cranes, conveyors, construction equipment, agricultural, and defence equipment, gears for large mills used for producing cement, grind iron ore, rubber, roll steel, etc.

However, poor surface finish of teeth profile produces additional dynamic forces and reduces the transmitting efficiency, in-service performances and life span and hence, finishing of gear teeth profile turns into a vital issue in present day scenario. Conventional gear finishing processes: gear grinding, gear shaving, gear honing, gear lapping are very much popular in mechanical industries for gear finishing but, these processes are having material hardness limitation as in these processes material is removed by mechanical abrasion and hence, the tool should be harder than the workpiece. Moreover, these processes are costly, time consuming and provide surface finish not upto the mark. These shortcomings necessitate the exploration of alternative gear finishing processes. Electrochemical honing $(\mathrm{ECH})$ has capabilities and potential to be developed as an alternative of conventional gear finishing processes and can play an important role as high-precision gear finishing method because being a hybrid machining process it has potential to overcome most the limitations of conventional gear finishing methods and at the same time offers most of the capabilities of the conventional gear finishing methods. It is a hybrid microfinishing process combining the faster material removal capability of electrochemical machining $(\mathrm{ECM})$ and functional surface generating capability of conventional honing. As in $\mathrm{ECH}$, most of the material is removed by electrolytic dissolution; 
workpiece of any material can be processed since, the material is conductive in nature.

The development of EC processes was stemmed by invention of Faraday's electrolysis principle and the association of electrolytic action to conventional honing started in 1962-1963 (Horgan, 1962; Eshelman, 1963). Initially, the purpose of electrolytic aid to conventional honing was just to improve the process productivity owing to the higher material removal achieved by the conventional honing process itself (Wilson, 1971). Budzynski $(1978,1980)$ is probably the first researcher who carried out research on ECH with his publication on ECH machine and theoretical details and technical factors of ECH after it is initiated by Randlett and Ellis (1967, 1968). But, the application of ECH for gear finishing was started by Capello and Bertoglio (1979) as they described the ECH for finishing the hardened cylindrical gear tooth face. The development of a productive, high-accuracy, long tool life, gear finishing method was described by Chen et al. (1981). Fig. 1 depicts the fundamental concept of ECH of gears explained by Chen et al. (1981). As shown in Fig. 1, the workpiece gear is rotated and reciprocated simultaneously with cathode gear and honing gear. The cathode gear is fabricated by sandwiching a conductive gear between two non-conductive gears and undercutting the profile of conductive gear than non-conductive gear to provide the inter-electrode gap (IEG) to prevent shortcircuit. The IEG is flooded with proper electrolyte and a DC source is applied to complete the circuitry. But, as EC action starts, due to generation of oxygen at cathode, a thin metal-oxide micro-film is generated on the workpiece which is insulating in nature and protects the surface from being further removed. Honing gear scrubs this insulating layers selectively to produce fresh metal and thus, accelerates the process.

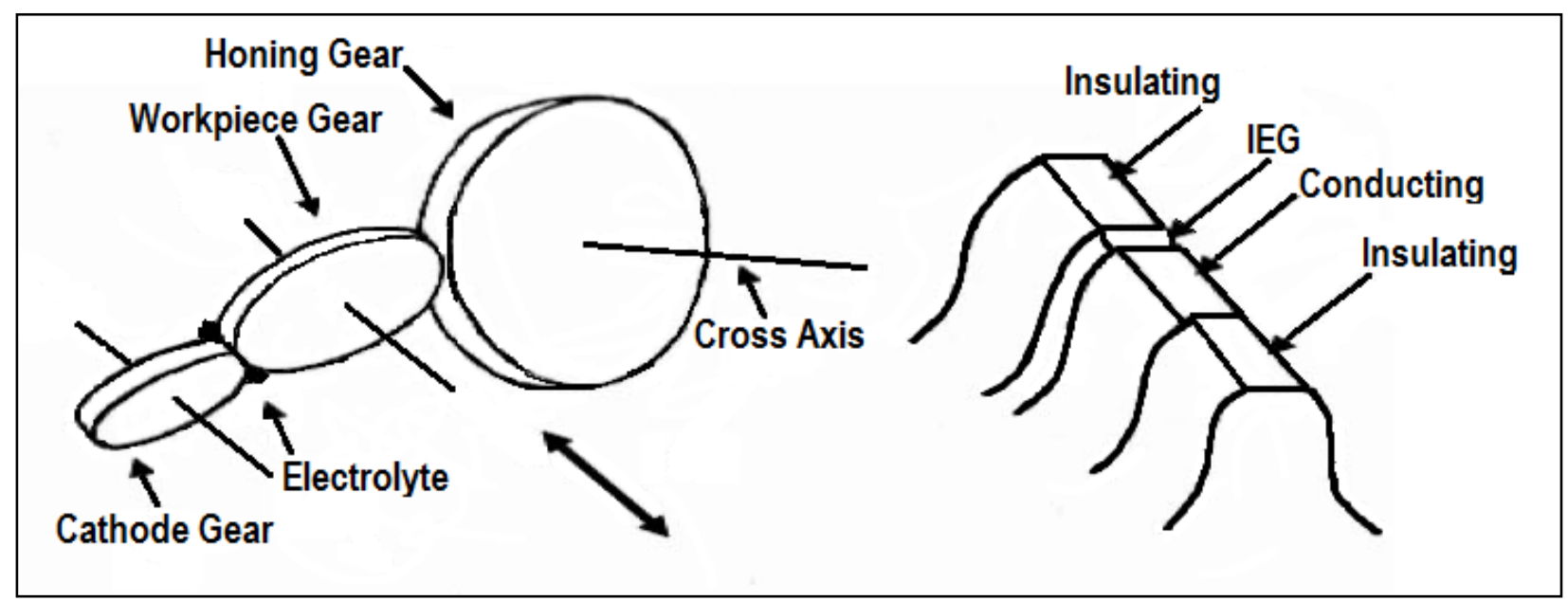

Fig. 1. Process principle of ECH of gears explained by Chen et al. (1981)

After that a number of researchers have been carried out experimental investigations on ECH of gears. A brief outline of research works carried out on gear finishing by ECH has been presented in Table 1. However, the process is still in infancy stage and yet to be commercialized in modern industries due to the complex tooling design and experimental setup. 
Misra, J. P.; Jain, P. K. \& Sevak, R.: Ech of Spur Gears - A Step Towards Commer...

\section{Researcher(s) and Year}

Capello and Bertoglio (1979)
Findings

Explained the concept of removing material from gear tooth face of the anodic helical gear having 17 teeth and module of 2.5 and is in mesh with a specially designed cathodic helical gear having 64 teeth.

The test bench was developed to provide reciprocal rotary motion to the electrodes with a controlled working gap.

The experimental outcomes established the viability of using ECH for gear finishing. However, it was found that the helix and involute profile obtained from the process were not yet acceptable.

Explained the problem of high quality gear manufacturing to smooth running at high speed.

$\checkmark$ Electrochemical action between the shaped cathode and work-piece gear teeth.

$\checkmark$ Rapid improvement of geometric accuracy in the work piece gear tooth profile.

Wei et al. (1986, 1987)

Described ECH as a fine machining process and a means to produce excellent surface quality.

* Explained a new method named Field Controlled Electrochemical Honing (FCECH).

He et al. (2000)

Explained a new working method of controllable Electro-Chemical Honing of gears using a special type gear shaped cathode.

Yi et al. (2000, 2002)
Described the electrochemical gear tooth profile-modification theory.

Explained a new process of axial modification for carbonized gears and investigated the current density distribution in the gear teeth.

Described a new method for electrochemical tooth-profile 


\begin{tabular}{|l|l|}
\hline & $\begin{array}{l}\text { modification based on real-time control } \\
\text { and established a mathematical model } \\
\text { of the electrochemical tooth profile } \\
\text { modification process using an artificial } \\
\text { neural network. }\end{array}$ \\
\hline $\begin{array}{l}\text { Naik (2008), Naik et al. (2008), Naik \& } \checkmark \text { Explained the effects of current, } \\
\text { Misra (2012) }\end{array}$ & $\begin{array}{l}\text { electrolyte concentration, electrolyte } \\
\text { composition and finishing time in } \\
\text { improving surface quality of spur gears }\end{array}$ \\
\hline Misra (2009) and Misra et al. (2010) & $\begin{array}{l}\text { Carried out experimental investigations } \\
\text { on ECH of helical gears }\end{array}$ \\
\hline Jianjun et al. (2009) & $\begin{array}{l}\checkmark \text { Reported the use of pulse power supply } \\
\text { in ECH to improve the result than ECH } \\
\text { under continuous current by providing } \\
\text { relaxation period to the machining } \\
\text { process during pulse-off time. }\end{array}$ \\
\hline Singh (2010) & $\begin{array}{l}\text { Studied the effect of using pulse power } \\
\text { supply in ECH of gears. }\end{array}$ \\
\hline
\end{tabular}

Tab. 1. Brief outline of past research works on ECH of gears

On the basis of comprehensive study of past research works, the problems associated with the existing experimental setup; which prevent the process from being commercialized are listed below:

- The existing experimental setup is complex in design and bulky in size as it deals with the meshing of workpiece gear with both cathode gear and honing gear.

- It is very much difficult to provide precision finishing to the full profile of gear as the cathode gear is developed by sandwiching conductive gear between two non-conductive gears and a IEG is provided to prevent shortcircuit.

- Moreover, the existing setup is developed for finishing gear of a certain diameter as there is no provision to accommodate workpiece gears of different sizes.

The present study discusses the noble approach to design and develop a tooling system to eradicate the above listed drawbacks of existing setup. The remainders of this chapter are organized as follows: the detail of recently developed experimental setup is given in section 2. The brief detail of parametric study has been included in section 3. Section 4 discusses the experimental detail. The outcomes of experimental study have been discussed in section 5. A comparative study of existing and recently developed setup is explained in section 6 . At section 7, conclusions are drawn and future scopes are outlined. 
Misra, J. P.; Jain, P. K. \& Sevak, R.: Ech of Spur Gears - A Step Towards Commer...

\section{Modified Experimental Setup}

In the recently developed setup, basic mechanism of material removal remains same but the procedure is different. Fig. 2 illustrates the process principle on the basis of which this experimental setup is designed and developed. Here, workpiece is simultaneously rotated and reciprocated with $\mathrm{ECH}$ tool which is fabricated by sandwiching a conductive gear between two non-conductive abrasive coated gears. The thickness of abrasive layer acts as IEG. A proper electrolyte is supplied at IEG to carry out the ECH process. As the workpiece is rotated and reciprocated simultaneously, the ECM and honing action take place concurrently and thus, the full profile of the gear teeth is finished. The photographic view of the machining chamber in which, the gear arrangement can be clearly observed is demonstrated in Fig. 3.

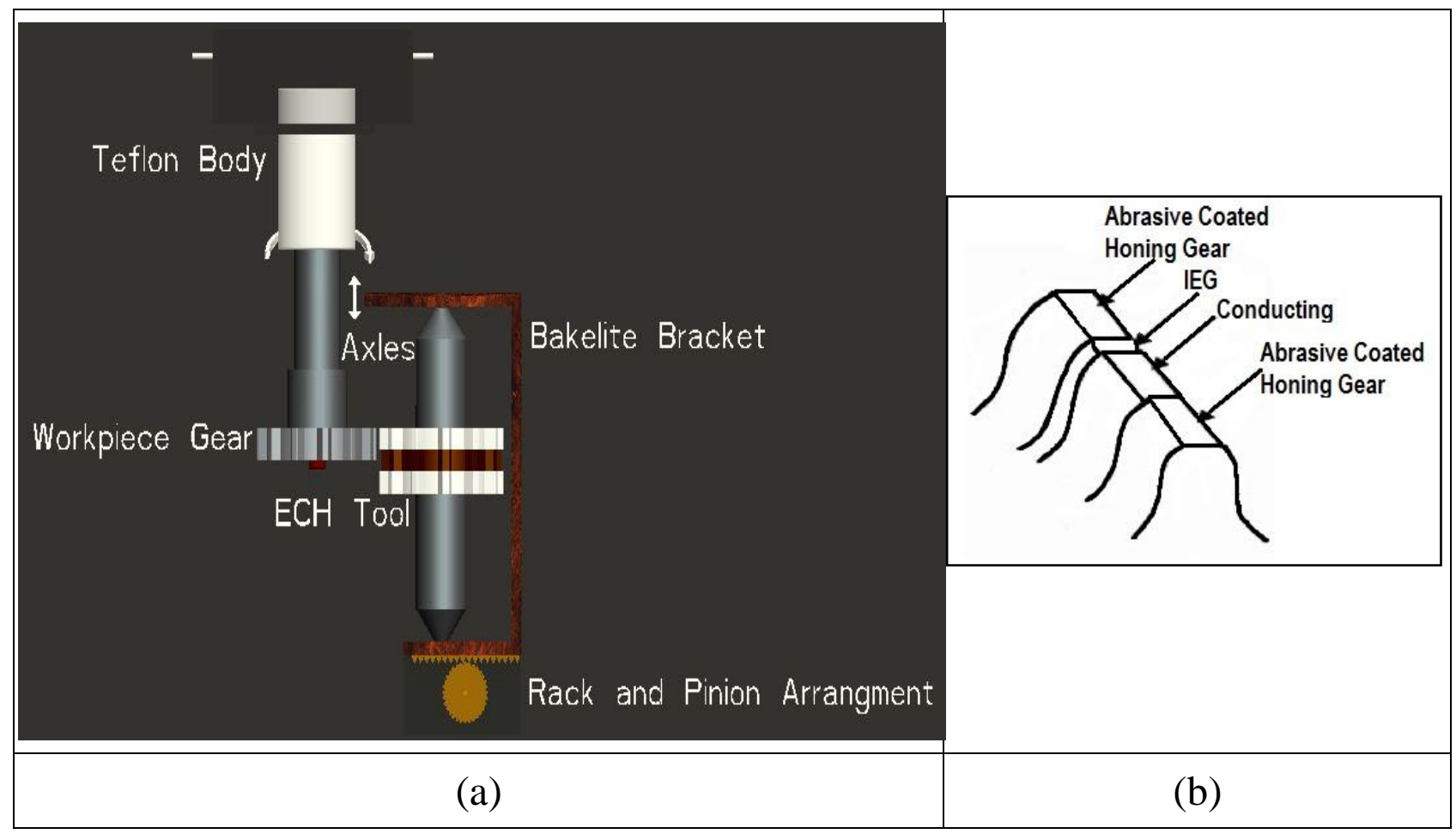

Fig. 2. Basic process principle of ECH of gears used in present experimental setup

This experimental setup consists of four major subsystems namely power supply system, electrolyte supply system, tooling and tool-motion system and machining chamber and fixtures. Among these four sub-elements, tooling and tool-motion system is most vital as it influences the process most significantly. In the present study, tooling system consists of workpiece gear and a specially shaped ECH tool. The ECH tool was fabricated by sandwiching a copper gear between two alumina abrasive bonded honing gear which distinguishes the present tooling system from the prior art (Chen et al., 1981; Jain et al., 2009). The detail specification of the workpiece gear and ECH tool is described in Table 2. The workpiece gear and the $\mathrm{ECH}$ tool was mounted on axles in such a way that proper meshing of workpiece and ECH tool can be easily achieved. The axles were made of stainless steel for its machinability, strength and corrosion resistance properties. The axle of workpiece gear was connected with the teflon body while the axle of ECH tool was hold by a 
bakelite bracket which was placed on a rack and pinion system for proper positioning and to accommodate different sizes of gears. The tool-motion systems consists of a DC induction motor for providing rotational motion to the workpiece and a programmable stepper motor to provide reciprocating motion. The new design of tooling system provides a number of benefits over previous such as comparatively simple and cost effective tooling system, full profile of the gear can be finished and it can accommodate different sizes of gears. A schematic diagram showing different elements of the setup is illustrated in Fig. 4.

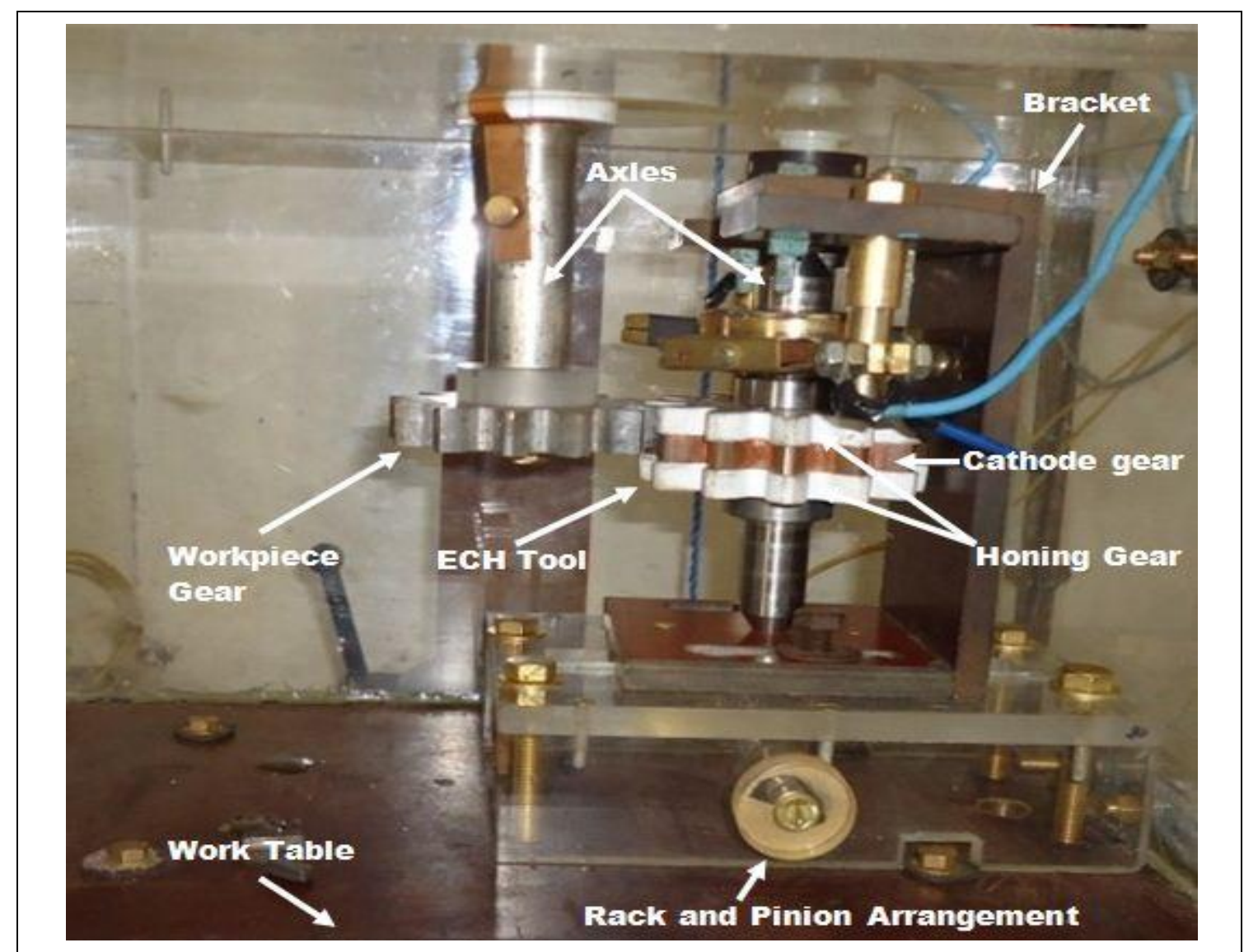

Fig. 3. Photographic view of machining chamber of the present experimental setup

\begin{tabular}{|l|l|}
\hline Workpiece Gear \\
\hline Specification & diametral pitch: 4, number of teeth: 12, face width: $15 \mathrm{~mm}$ \\
\hline Material & $\begin{array}{l}\text { EN } 8 \text { (Fe } \approx 98.44 \%, C \approx 0.39 \%, S i \approx 0.35 \% \text { and } \mathrm{S} \approx 0.34 ; \text { EDX } \\
\text { Analysis) }\end{array}$ \\
\hline ECH Tool: Cathode gear is sandwiched between two honing gears \\
\hline Cathode gear & diametral pitch: 4, number of teeth: 12, face width: $10 \mathrm{~mm}$ \\
\hline Specification & Copper \\
\hline Material & diametral pitch: 4, number of teeth: 12, Face width: $10 \mathrm{~mm}$ \\
\hline Honing gear & $\begin{array}{l}\text { EN 8 (abrasive coated with alumina, grain Size: } 5-45 \mu \mathrm{m}, \\
\text { coating thickness: } 500 \mu \mathrm{m})\end{array}$ \\
\hline Specification & Material
\end{tabular}

Tab. 2. Brief detail of workpiece gear and ECH tool 


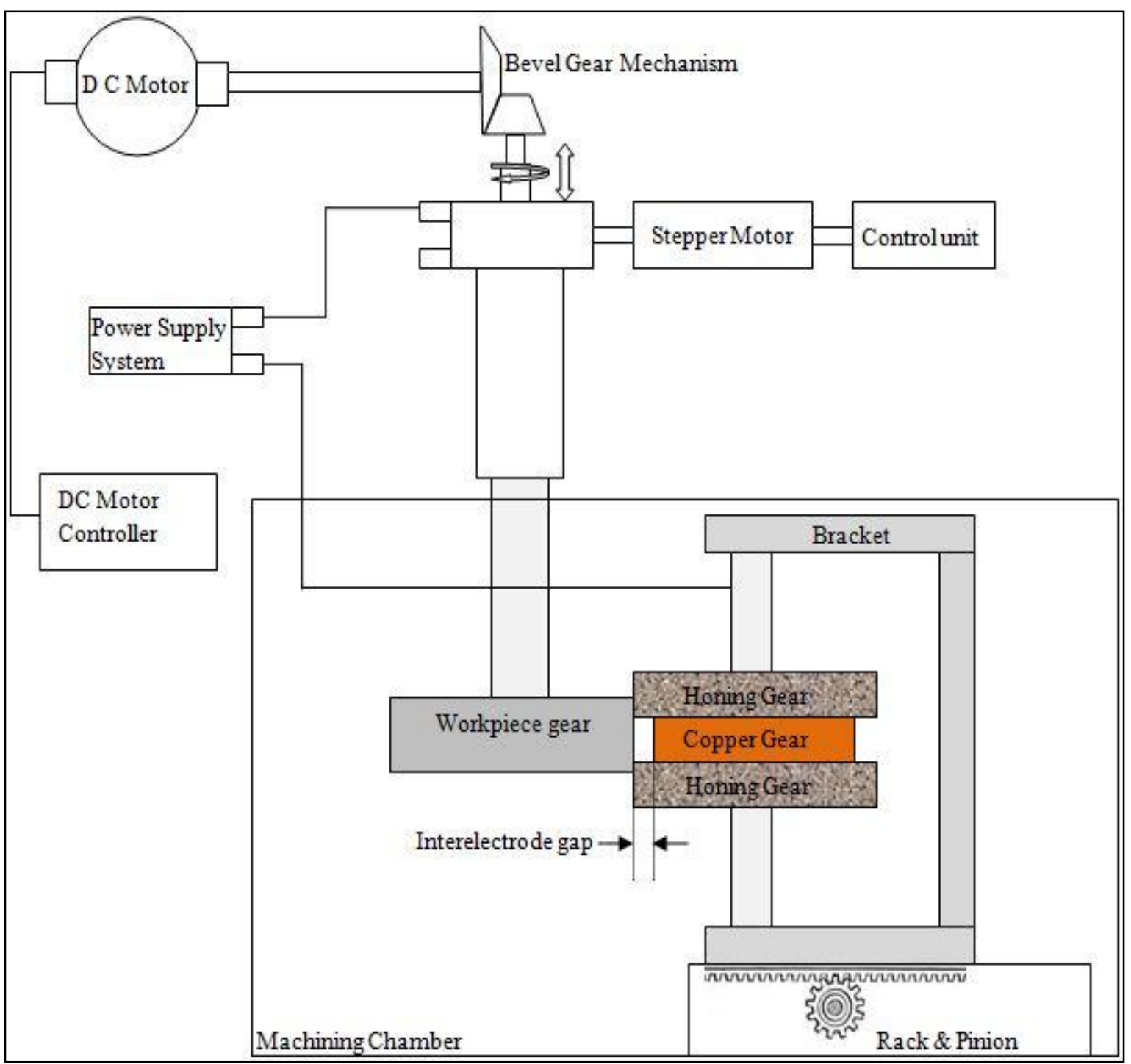

Fig. 4. Schematic diagram of recently developed experimental setup for ECH of gears

\section{Parametric Study}

ECH process parameters can be classified into four groups: power supply related parameters, electrolyte related parameters, honing related parameters and workpiece and tooling related parameters. The inter-relationship of $\mathrm{ECH}$ parameters and $\mathrm{ECH}$ performance characteristics is presented using Ishikawa's Cause-Effect diagram in Fig. 5. For the present study, finishing time, current and rotating speed of the workpiece were used as input process parameters while percentage improvement in average surface roughness $\left(\mathrm{PIR}_{\mathrm{a}}\right)$ and maximum surface roughness $\left(\mathrm{PIR}_{\mathrm{tm}}\right)$ and amount of material removed (MR) were used as response parameters. Table 3 presents the ranges and levels of input process parameters selected for experiments.

\section{Experimental Details}

\subsection{Experimental Procedure}

Experimentation has been carried out in two phases: pilot experiments to decide the electrolyte composition and the range of finishing time for main experimentation; 
main experiments to evaluate the effect of input parameters on response parameters. The surface characteristics of gear teeth profile before and after the process were observed using optical profilometer and scanning electron microscope. The $\operatorname{PIR}_{\mathrm{a}}$ and PIR $_{\mathrm{tm}}$ values were calculated using following equations.

$$
\begin{aligned}
\operatorname{PIR}_{\mathrm{a}} & =\frac{\text { initial } R_{\mathrm{a}} \text { value }- \text { final } R_{\mathrm{a}} \text { value }}{\text { initial } R_{\mathrm{a}} \text { value }} \\
\mathrm{PIR}_{\mathrm{tm}} & =\frac{\text { initial } R_{\mathrm{tm}} \text { value }- \text { final } R_{\mathrm{tm}} \text { value }}{\text { initial } \mathrm{R}_{\mathrm{tm}} \text { value }}
\end{aligned}
$$

The amount of material removed was quantified by measuring the mass of workpiece before and after the process and using the following equation.

$$
\text { MR = Mass of workpiece before ECH - Mass of workpiece after ECH }
$$

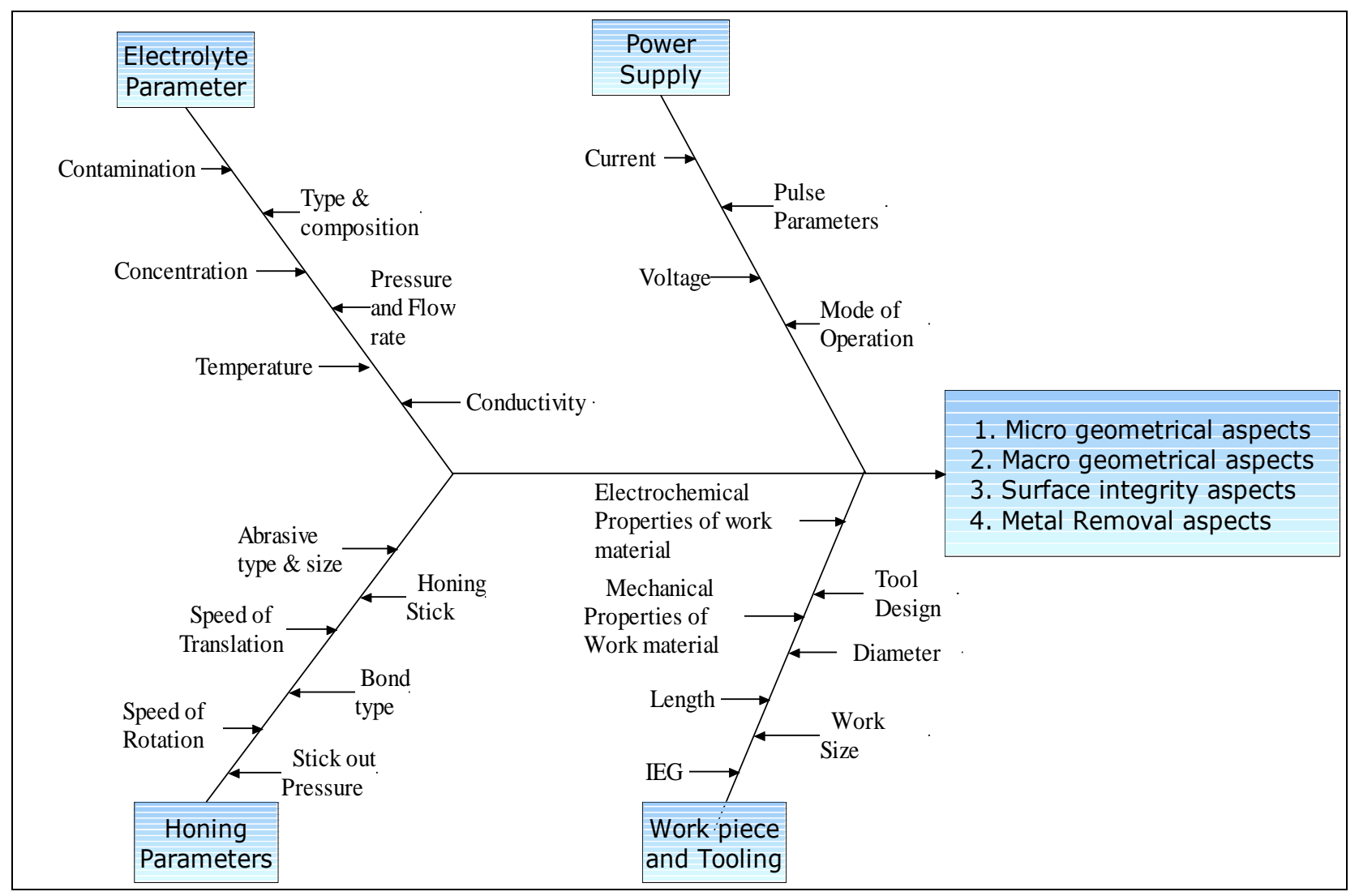

Fig. 5. Ishikawa's cause-effect diagram for ECH process parameters

\begin{tabular}{|c|c|c|c|c|c|}
\hline \multirow{2}{*}{ Parameter } & \multirow{2}{*}{ Designation } & \multirow{2}{*}{ Range } & \multicolumn{3}{|c|}{ Levels } \\
\cline { 4 - 6 } & & & L1 & L2 & L3 \\
\hline Finishing time (min) & $\mathrm{T}$ & $2-6$ & $2(-1)$ & $4(0)$ & $6(1)$ \\
\hline Current (A) & $\mathrm{I}$ & $10-30$ & $10(-1)$ & $20(0)$ & $30(1)$ \\
\hline Rotating Speed (rpm) & $\mathrm{S}$ & $50-80$ & $50(-1)$ & $65(0)$ & $80(1)$ \\
\hline
\end{tabular}

Tab. 3. Levels and ranges of input process parameters. 
Misra, J. P.; Jain, P. K. \& Sevak, R.: Ech of Spur Gears - A Step Towards Commer...

\subsection{Experimental Design}

The main experimentation was planned according to the box-behnken design (BBD) of response surface methodology (RSM) devised by G. E. P. Box and D. Behnken. Box and Behnken have proposed some three level designs for fitting response surfaces. These designs are formed by combining $2 \mathrm{k}$ factorials with incomplete block designs and the resulting designs are very efficient in terms of the number of required experimental runs. Main experimentation consists of three factors (i.e. finishing time, current and rotating speed) each at three levels as mentioned in the Table 2 and hence, total fifteen trial runs including three replications of the centre point are required (Montgomery, 2004) Table 4 shows the parametric combinations for different trials used in the main experimentation.

\begin{tabular}{|c|c|c|c|}
\hline \multirow{2}{*}{$\begin{array}{c}\text { Experiment } \\
\text { No. }\end{array}$} & \multicolumn{3}{|c|}{ Level (Value) of Process Parameters } \\
\cline { 2 - 4 } & Finishing Time & Current & Rotating Speed \\
\hline 1 & $(-1) 2$ & $(-1) 10$ & $(0) 65$ \\
\hline 2 & $(1) 6$ & $(-1) 10$ & $(0) 65$ \\
\hline 3 & $(-1) 2$ & $(1) 30$ & $(0) 65$ \\
\hline 4 & $(1) 6$ & $(1) 30$ & $(0) 65$ \\
\hline 5 & $(-1) 2$ & $(0) 20$ & $(-1) 50$ \\
\hline 6 & $(1) 6$ & $(0) 20$ & $(-1) 50$ \\
\hline 7 & $(-1) 2$ & $(0) 20$ & $(1) 80$ \\
\hline 8 & $(1) 6$ & $(0) 20$ & $(1) 80$ \\
\hline 9 & $(0) 4$ & $(-1) 10$ & $(-1) 50$ \\
\hline 10 & $(0) 4$ & $(1) 30$ & $(-1) 50$ \\
\hline 11 & $(0) 4$ & $(-1) 10$ & $(1) 80$ \\
\hline 12 & $(0) 4$ & $(1) 30$ & $(1) 80$ \\
\hline 13 & $(0) 4$ & $(0) 20$ & $(0) 65$ \\
\hline 14 & $(0) 4$ & $(0) 20$ & $(0) 65$ \\
\hline 15 & $(0) 4$ & $(0) 20$ & $(0) 65$ \\
\hline
\end{tabular}

Tab. 4. Three factors three levels Box-Behnken design along with the parameter Values for different runs

\section{Results and Discussions}

\subsection{Study of Pilot Experiments}

In ECH process, most of the material is removed by electric dissolution, while honing produces the favourable machining condition and hence, a proper coordination between them provides the best outcomes. To study the process behaviour, trial runs were carried out using $7.5 \% \mathrm{NaCl}$ as electrolyte for a single minute. But, it was found that the excessive formation of oxide layers on worksurface and due to which it was found difficult to measure the surface roughness parameters using optical profilometer. This is owing to higher rate of electrolytic action than honing action which was lacking from scrubbing the oxide layers produced by the process. From the observation of trial runs, it was evident that the finishing time of 
single minute was not sufficient and hence, two to six minutes were fixed as finishing time for experimental study. In addition, to get better passivation effect, the same volume of $\mathrm{NaNO}_{3}$ was added in the electrolyte to produce $7.5 \%(\mathrm{NaCl}+\mathrm{NaNO} 3)$ electrolytic solution. Moreover, the procedure of conducting experiments were fixed as two minute of ECH action followed by one minute of simple honing for complete removal of insulting metal-oxide micro-film from worksurface for better ECM action.

\subsection{Study of Main Experiments}

The responses were plotted against the process inputs to investigate the effects of input process parameters on $\mathrm{PIR}_{\mathrm{a}}, \mathrm{PIR}_{\mathrm{tm}}$ and $\mathrm{MR}$ and finally optimization was performed to find the optimum combination of process parameters to conduct confirmation experiments. Effects of finishing time, current and rotating speed on response parameters are shown in Figs. 6 (a), (b) and (c) respectively. The regression models were developed for $\mathrm{PIR}_{\mathrm{a}}, \mathrm{PIR}_{\mathrm{tm}}$ and MR in terms of actual values to predict the response parameters for a given set of input parameters and are described by equations (4), (5) and (6) respectively.

$$
\begin{aligned}
& P I R_{a}=68.09392+3.13062 * T-0.23225 * I-0.13142 * S \\
& P I R_{t m}=71.212175+3.70812 * T-0.23500 * I-0.13158 * S \\
& M R=585.82467+124.36750 * T-8.31250 * I-4.12467 * S
\end{aligned}
$$

In $\mathrm{ECH}$, material is removed by combine action of electrolytic dissolution and scrubbing action. According to the Faraday's principle of electrolysis, the amount of material removed in ECM is directly proportional with the processing time. The effect of finishing time on $\mathrm{PIR}_{\mathrm{a}}, \mathrm{PIR}_{\mathrm{tm}}$ and MR is presented in Fig. 6 (a). It was found that the values response parameters increase with increasing finishing time. Higher finishing time provides the longer period for electrolytic dissolution and for scrubbing action; due to which material removal increases and the irregularities of gear teeth surface minimize which results in increasing $\operatorname{PIR}_{\mathrm{a}}$ and $\operatorname{PIR}_{\mathrm{tm}}$. 
$\overline{\text { Misra, J. P.; Jain, P. K. \& Sevak, R.: Ech of Spur Gears - A Step Towards Commer... }}$

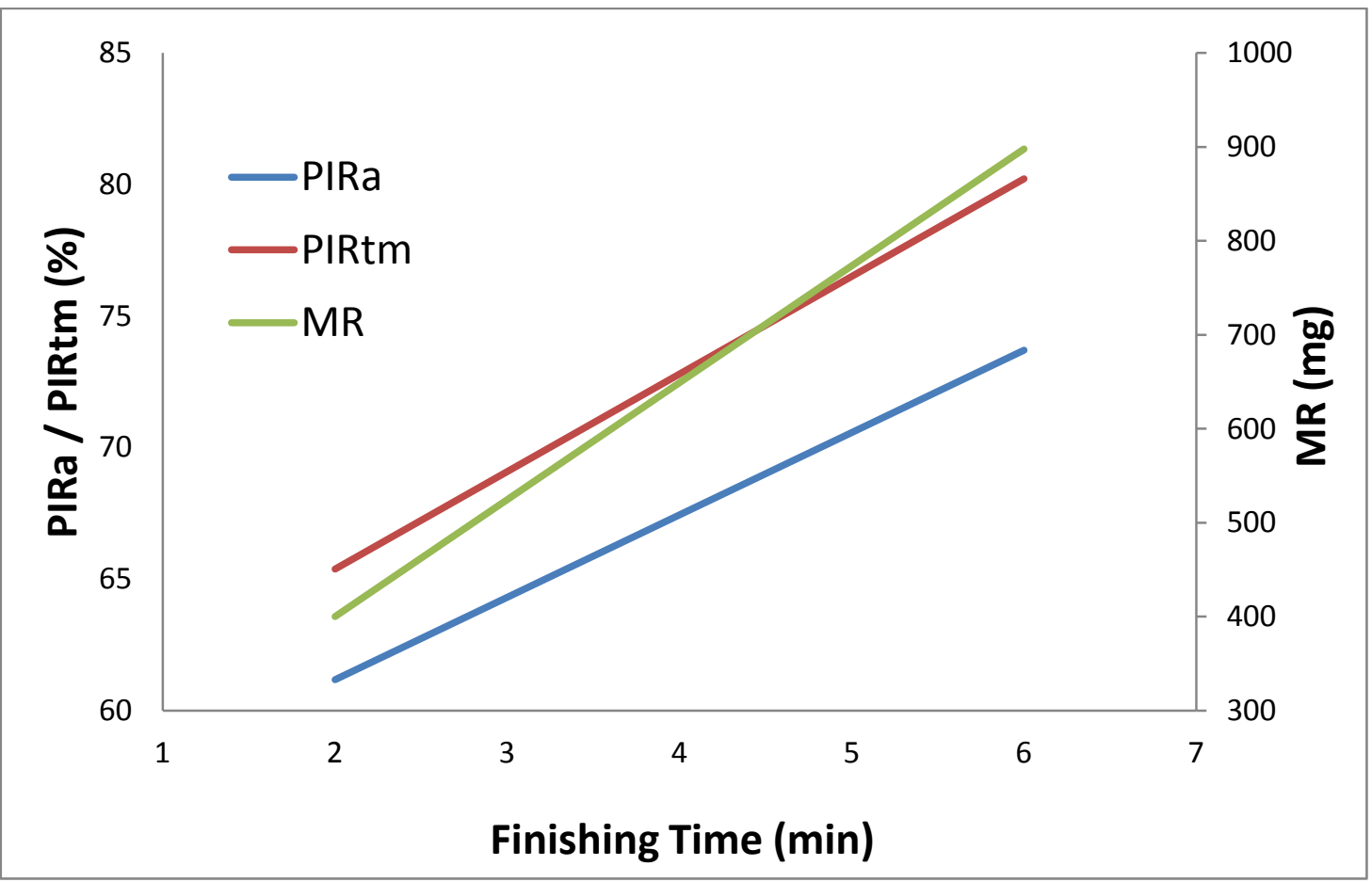

(a)

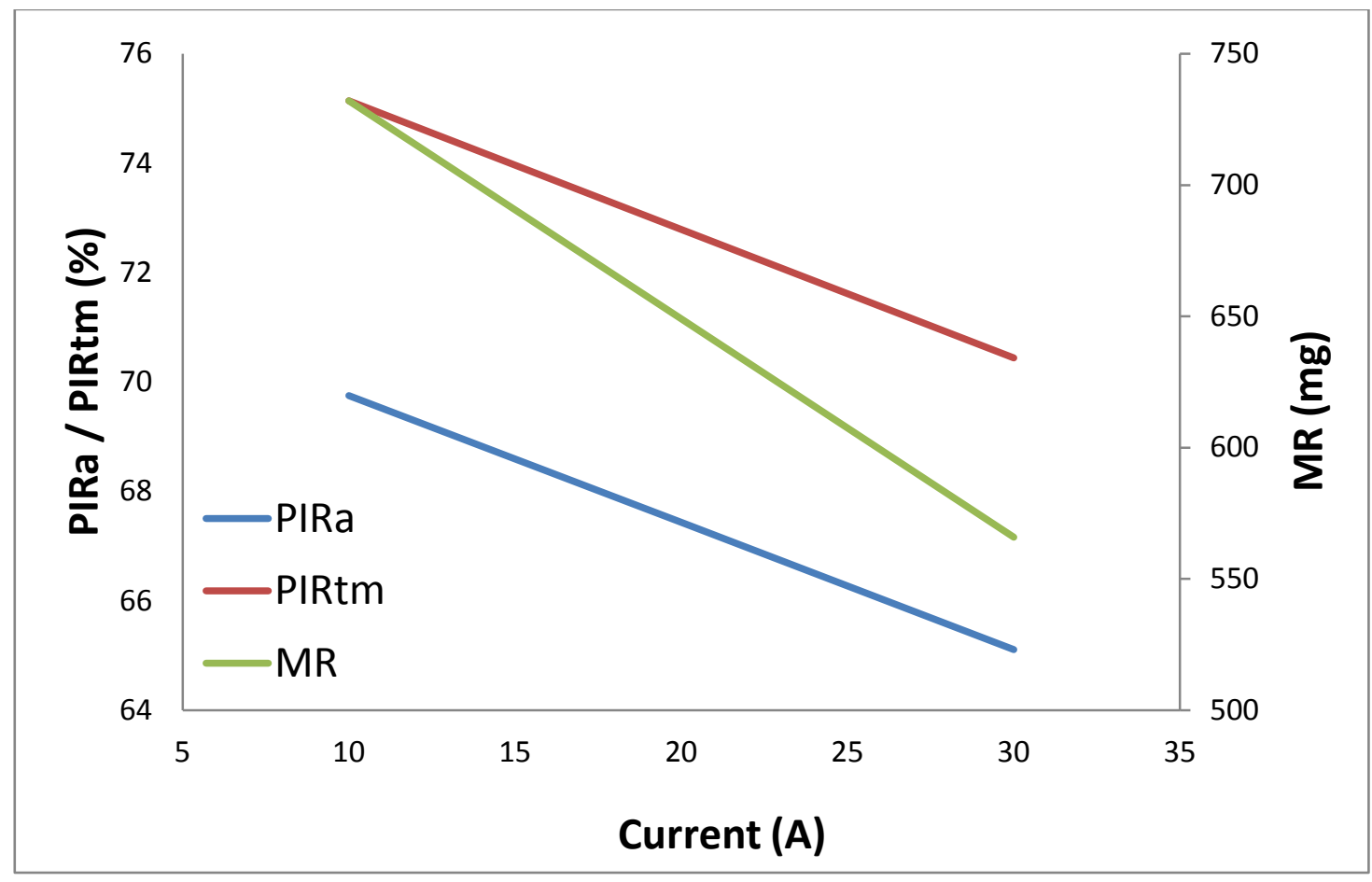

(b) 


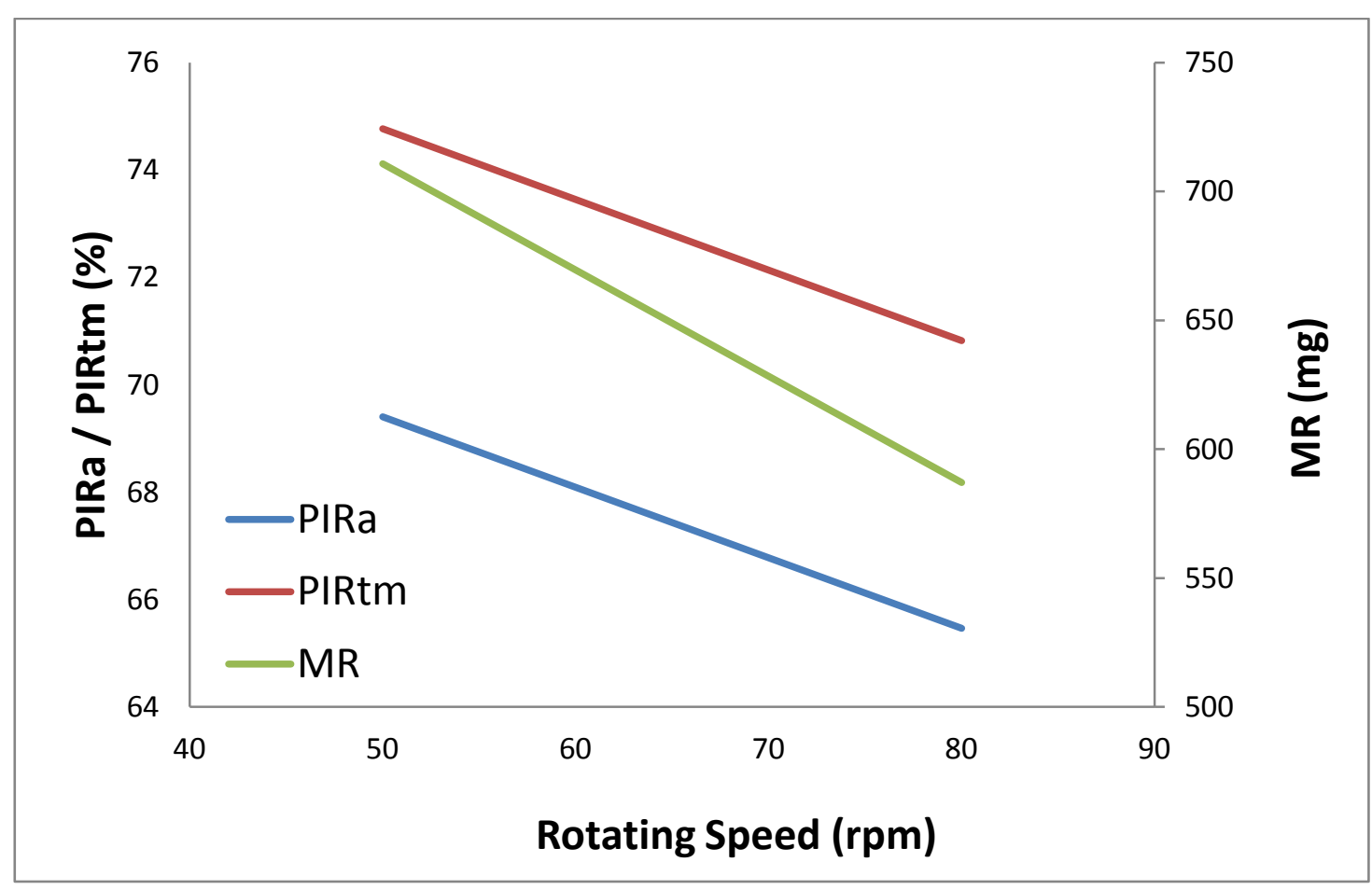

(c)

Fig. 6. Effect of input process parameters on response parameters

Fig. 6 (b) depicts the effect of current on $\mathrm{PIR}_{\mathrm{a}}, \mathrm{PIR}_{\mathrm{tm}}$ and MR. It is observed that values of $\mathrm{PIR}_{\mathrm{a}}, \mathrm{PIR}_{\mathrm{tm}}$ and MR decrease with increase in current. During the process, as time progresses, the IEG increases due to removal of material from workpiece gear. As IEG increases, the effect of current on material removal decreases and as a result PIR , PIR $_{t m}$ and MR also decreases with increase in current.

It is evident from Fig. 6 (c) that with increase in rotating speed, values of response parameters decrease. At lower rotating speed of the workpiece gear, the ECM process gets enough time to remove the material, while at higher rotating speeds; the ECM process does not get enough time to remove the material. Moreover, at lower rotating speed, the torque and therefore so force applied by the gear teeth increases which results in higher abrasive action and so higher $\operatorname{PIR}_{a}, \operatorname{PIR}_{t m}$ and MR.

\section{Comparative Study}

In this section a brief comparison between the outcomes of newly developed experimental setup and existing setup has been carried out. Naik et al. has been carried out experimental study on ECH of spur gears using existing setup and found

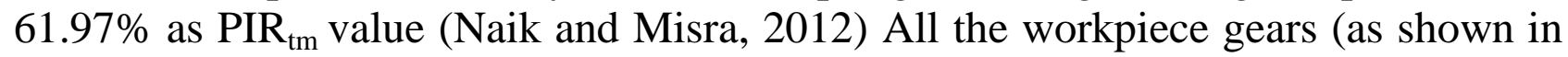
Fig. 7 (a)) polished by Naik et al. are of same size as there was no provision in the existing setup for accommodating workpiece gears of different sizes while in the present experimental study, experimentation has been carried out for three different sizes gears as shown in Fig. 7 (b). In the present study, the minimum surface roughness value obtained $\left(\mathrm{R}_{\mathrm{a}}=857.56 \mathrm{~nm}\right)$ is far better than the result obtained from existing setup (Naik and Misra, 2012). 


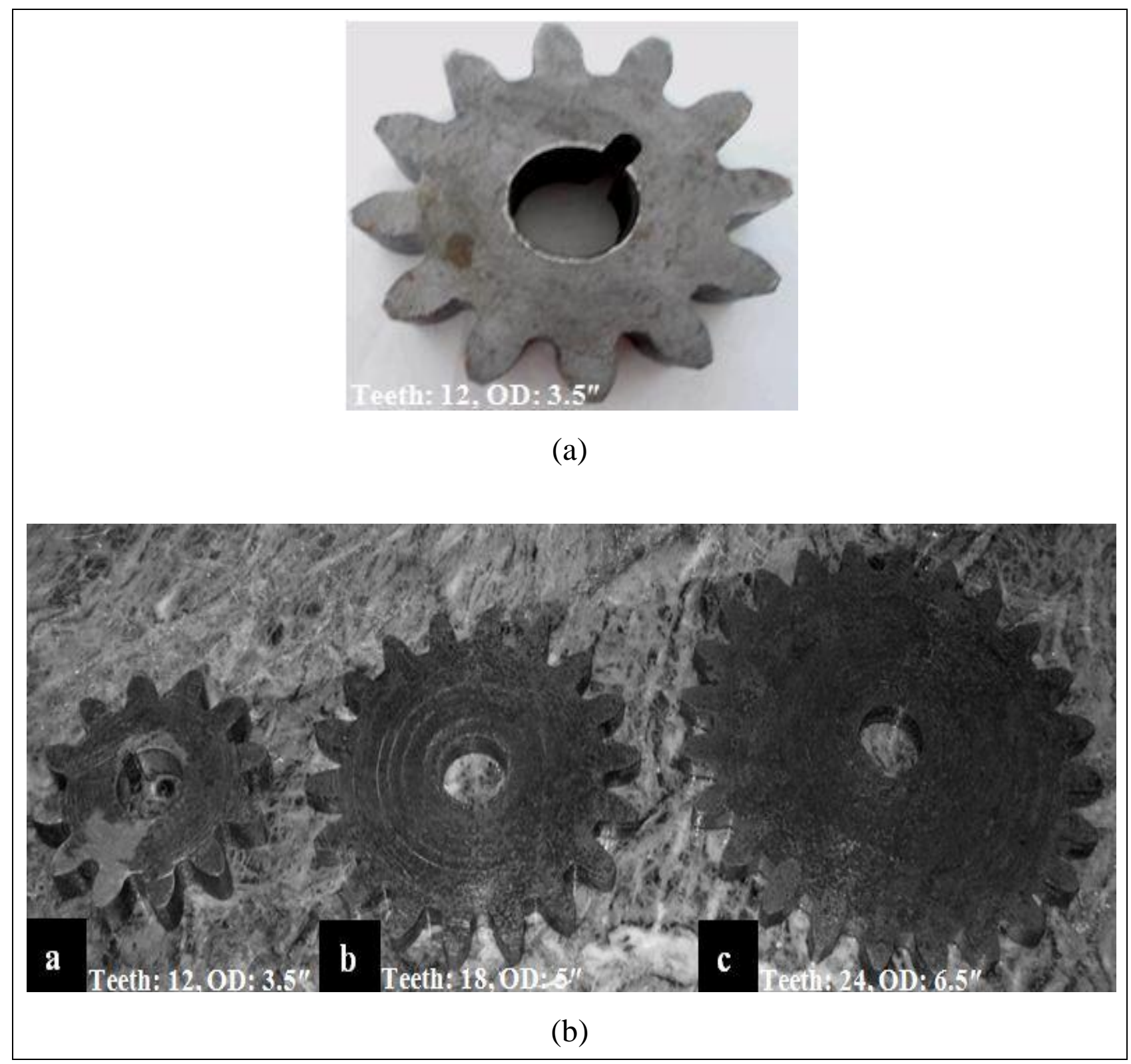

\section{Conclusions and Future Scope}

The study of finishing of spur gears by ECH process using an indigenously developed tooling system has been carried out. The key features of this experimental setup are highlighted and the benefits of this setup over existing setup are also discussed. It was evident from the present study, that the modified setup is capable of accommodating different sizes of gears and produce better surface finish than the existing setup. The feasibility of using the modified setup commercially was also established.

But, this experimental setup still has some limitations. This setup can be used only for gears transmitting motion between parallel shafts (e.g., spur, helical) as the present setup is unable to accommodate gears transmitting motion between nonparallel shafts (e.g., bevel, worm). The present study has been carried out with alumina abrasives of a certain particle size; finer abrasive particles may provide 
better outcome in terms of surfacing in expense of material removal rate. Therefore, further study is required in this context to design and develop the setup to accommodate all types of gears without setup changeover.

\section{Acknowledgement}

The authors wish to acknowledge the financial support obtained from DST, New Delhi, India under grant no SR/S3/MERC-0068/2010(G). The authors also wish to acknowledge the technical information obtained from Mr. Ramlal Naik.

\section{References}

Budzynski, A. F. (1978). Electrochemical Honing Machine. Polish Technical Review, Vol. 12, 2-3

Budzynski, A. F. (1980). Theoretical principles and technical factors of electrochemical honing, International Symposium on Electro Machining (ISEM)-6, Krakow

Capello, G. \& Bertoglio, S. (1979). A New Approach by Electrochemical Finishing of Hardened Cylindrical Gear Tooth Face. CIRP Annals, Vol. 28, No. 1, 103107, 00078506

Chen, C. P.; Liu, J.; Wei, G. C.; Wan, C. B. \& Wan, J. (1981). Electrochemical Honing of Gears: A New Method of Gear Finishing. CIRP Annals, Vol. 30, No.1, 103-106, 00078506

Dudley, D. W. (1984). Handbook of Practical Gear Design, McGraw-Hill, 0070179514, New York

Davis, J. R. (2005). Gear Materials, Properties, and Manufacture, ASM International, 0871708159, Ohio

Eshelman, R. H. (1963). Electrochemical Honing Reports Ready for Production Jobs. Iron Age, 124

He, F.; Zhang, W. \& Nezu, K. (2000). A Precision Machining of Gears (A Slow Scanning Field Controlled Electrochemical Honing). JSME International Journal Series C, Vol. 43, No. 2, 486-491, 13447653

Horgan, I. F. (1962). Electrolytic boost for honing. American Mach.

Jain, N. K.; Naik, L. R.; Dubey, A. K. \& Shan, H. S. (2009). State-of-art-review of Electrochemical Honing of Internal Cylinders and Gears, Proc. IMechE: Journal of Engineering Manufacture, Vol. 223, No. 6, 665-681, 20412975

Jianjun, Y.; Yujie, D.; Shaohua, Z.; Baiyangand, J. \& Jingjing, Z. (2009). A Novel Technique of Polishing Gear Working Surface Using PECMP. International Journal of Precision Engineering and Manufacturing, Vol. 10, No. 4, 57-62, 20054602 
Misra, J. P.; Jain, P. K. \& Sevak, R.: Ech of Spur Gears - A Step Towards Commer...

Misra, J. P. (2009). Precision finishing of helical gears by electrochemical honing $(\mathrm{ECH})$ process. M.Tech Dissertation, Mechanical \& Industrial Engineering Department, IIT Roorkee

Misra, J. P.; Jain, N. K. \& Jain, P. K. (2010). Investigations on precision finishing of helical gears by electrochemical honing (ECH) process, Proc. IMechE: Journal of Engineering Manufacture, Vol. 224, No. 12, 1817-1830, 20412975

Montgomery, D. C. (2004). Design and Analysis of Experiments, Wiley-India, 0470128666, New Delhi

Naik, L. R. (2008). Investigation on precision finishing of gears by ECH. M.Tech Dissertation, Mechanical \& Industrial Engineering Department, IIT Roorkee

Naik, L. R.; Jain N. K. \& Sharma, A. K. (2008). Investigation on precision finishing of spur gears by electrochemical honing, Proc. 2nd Int. and 23rd AIMTDR Conf., Shunmugam, M. S. \& Rameshbabu, N. (Ed.) pp. 509-514, Chennai

Naik, R. \& Misra, J. P. (2012). Parametric optimization of ECH of spur gears by Taguchi technique, Int. J. Materials and Product Technology, Vol. 43, No. 1/2/3/4, 84-101, 1741-5209

Randlett Jr., E. A. \& Ellis, M. P. (1967). Electrochemical Honing. American Society of Tools and Manufacturing Engineers (ASTME), Technical Paper MR67-648, $1-13$

Randlett Jr., E. A. \& Ellis, M. P. (1968). Electrochemical Honing - ECH. American Society of Tools and Manufacturing Engineers (ASTME), Technical Paper MR68-815, 1-11

Singh, H. (2010). Experimental investigation of precision finishing of spur gears by pulse-electrochemical honing ( $\mathrm{PECH})$ process. M.Tech Dissertation, Mechanical \& Industrial Engineering Department, IIT Roorkee

Wei, G.; Wu, M. \& Chen, C. (1986). An Investigation into the Ability of Correcting Error in ECH. CIRP Annals, Vol. 35, No. 1, 125-127, 00078506

Wei, G.; Wang, Z. \& Chen, C. (1987). Field Controlled Electrochemical Honing of Gears. Precision Engineering, Vol. 9, No. 4, 218-221, 01416359

Wilson, J. F. (1971). Practice \& Theory of Electrochemical Machining, John Wiley, 0471949701, New York

Yi, J.; Yang, T. \& Zhou, J. (2000). New electrochemical processes gear tooth-profile modification. Mfg. Tech. and Modern Machine, Vol. 9, No. 1, 102-105

Yi, J.; Zhang, J.; Yang, T.; Xia, D. \& Hu, D. (2002). Solving the control problem for electrochemical gear tooth-profile modification using an artificial neural network. International Journal of Advanced Manufacturing Technology, Vol. 19, No. 1, 8-13, 14333015 